\title{
Los Dioses Ajenos: Apuntes sobre \#\#\#\#\#\# y \#\#\#\#\#\# como instrumentos de polémica religiosa ${ }^{1}$
}

\author{
Valenzuela Avaca, Eduardo \\ Los Dioses Ajenos: Apuntes sobre \#\#\#\#\#\# y \#\#\#\#\# como instrumentos de polémica religiosa ${ }^{1}$ \\ Synthesis, vol. 26, núm. 2, 2019 \\ Universidad Nacional de La Plata, Argentina \\ Disponible en: http://www.redalyc.org/articulo.oa?id=84662943001 \\ DOI: https://doi.org/10.24215/1851779Xe058
}

Esta obra está bajo una Licencia Creative Commons Atribución-NoComercial-Compartirlgual 4.0 Internacional. 
Artículos

\title{
Los Dioses Ajenos: Apuntes sobre $\varepsilon i \delta \omega \lambda$ ov y $\delta \alpha i \mu \omega \nu$ como instrumentos de polémica religiosa ${ }^{1}$
}

\section{The Alien Gods: Notes on $\varepsilon i \delta \omega \lambda \circ \nu$ and $\delta \alpha i \mu \omega \nu$ as Instruments of Religious Polemics}

Eduardo Valenzuela Avaca

DOI: https://doi.org/10.24215/1851779Xe058

Facultad de Filosofia y Humanidades, Universidad de

Redalyc: http://www.redalyc.org/articulo.oa?id=84662943001

\section{Chile, Chile}

ejvalena@uc.cl

(D) http://orcid.org/0000-0003-4681-3587

Recepción: 10 Junio 2019

Aprobación: 25 Octubre 2019

\section{Resumen:}

El presente estudio tiene como propósito reflexionar en torno a los potenciales polémicos asociados al traslado de las Escrituras hebreas al griego -la llamada Septuaginta (S. III a.C.)-, y el impacto que tendrán en la misión cristiana. Se propone, como hipótesis primaria, que las voces griegas eidolon ( $(\varepsilon \delta \delta \omega \lambda$ ) y daimon $(\delta \alpha i \mu \omega \nu)$ no ingresan a la Septuaginta por criterios de pertinencia traductológica, como alternativas más o menos precisas a ciertas voces hebreas, sino como recursos heurísticos llamados a contestar a la pregunta por la naturaleza de los dioses ajenos. Ambos conceptos - $\varepsilon i \delta \delta \omega \lambda \circ \nu$ y $\delta \alpha i \mu \omega \nu$ - serán utilizados para traducir no una sino numerosas voces hebreas. Se sostiene, en segundo término, que la amplitud y diversidad de voces hebreas sustituidas por $\varepsilon \Uparrow \delta \omega \lambda \lambda$ y y $\delta a i \mu \omega \nu$ trajo consigo la acumulación de diversas retóricas polémicas sobre los dioses ajenos, que otorgarán los fundamentos hermenéuticos y el sustento canónico para la construcción de las futuras voces ídolo y demonio.

Palabras Clave: Ídolo, Demonio, Septuaginta, Polémica religiosa, Traducción.

\begin{abstract}
:
The purpose of this study is to ponder the controversial potentials arising from the translation of the Hebrew Scriptures into Greek -the so-called Septuagint (3rd century BC) - and the impact they will have on the Christian mission. It is proposed, as

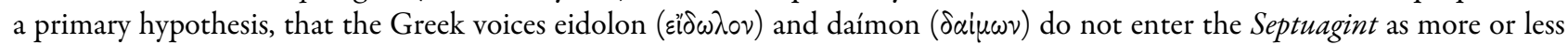
precise alternatives to certain Hebrew voices, but as heuristic resources meant to answer the question about the nature of the Alien Gods. Both concepts - $\varepsilon i \delta \omega \lambda$ ov and $\delta \alpha i \mu \omega \nu-$ are used to translate not one but many Hebrew voices. It is argued, in the second place, that the amplitude and diversity of Hebrew voices substituted by $\varepsilon i \delta \omega \lambda \circ \nu$ and $\delta \alpha i \mu \omega \nu$ brought with it the accumulation of diverse controversial rhetorics about the Alien Gods, which will grant the hermeneutical foundations and the canonical sustenance for the construction of idol and demon voices.
\end{abstract}

KEYWORDS: Idol, Demon, Septuagint, Religious polemics, Translation.

\section{INTRODUCCIÓN}

Alejandría - corazón del mundo helénico- albergaba para el siglo III a.C. una reconocible comunidad judeohelénica de la llamada diáspora. A diferencia del judaísmo palestino, que recibía la helenización con dificultad, elaborando literatura apocalíptica y expresando serios conflictos internos entre tradicionalistas y helenistas, ${ }^{2}$ la situación de los judeo-helenos era radicalmente distinta. No eran exiliados forzosos, sino comunidades en diáspora. Su apertura al ambiente helenístico puede observarse no solo en el uso de nombres griegos o en el uso de los tribunales de Alejandría - pese a tener sus propias instituciones legales-, sino también por su permanente lucha por obtener una ciudadanía en paridad con los griegos. ${ }^{3}$ Quizás el más evidente de los ejemplos de adaptación al medio helénico sea la masiva empresa traductológica y hermenéutica asociada al traslado de sus Escrituras desde el hebreo a la koiné griega. A esta obra se conocerá como Septuaginta. ${ }^{4}$ 
Se trata de un texto profundamente influyente. Para la mayoría de los escritores del Nuevo Testamento, la Septuaginta (en adelante LXX) constituyó su única Escritura, y el cristianismo temprano, en su conjunto, fue articulado a partir de los textos bíblicos en griego y no de los originales en hebreo. ${ }^{5}$ Un siglo más tarde, escritores del cristianismo temprano, como Justino Mártir y aún polemistas paganos como Celso acudirán a la LXX para sostener sus argumentaciones. La Vetus Latina -protoforma de la Vulgata- será precisamente una traducción que tendrá a la LXX como modelo. Su importancia no se restringe al campo teológico. Voces como idolo y demonio gatillarán procesos históricos de enorme magnitud, como la evangelización de las comunidades americanas o la persecución de la brujería, ambos en los albores de la Modernidad.

La Septuaginta tiene como lector ideal a la intelectualidad helénica. En un registro conocido como Carta de Aristeas, se afirma que la "ley divina" de Moisés había sido trasladada al griego por setenta y dos redactores judíos traídos desde Jerusalén a pedido del faraón helénico Ptolomeo II Philadelpho (285-246 a.C.), quien deseaba tener una copia de los escritos hebreos entre los tesoros de la famosa Biblioteca de Alejandría. Aunque sepamos que la Carta de Aristeas es realmente una epístola apologética, que no fue escrita por un griego contemporáneo de la corte de Ptolomeo II sino por un judeo-heleno anónimo en el siglo II a.C., ${ }^{6}$ apodado convencionalmente como Pseudo-Aristeas, resulta interesante observar que la raison d'être continúa siendo la idea de establecer un diálogo con el medio helénico. Un siglo más tarde, comenzarán a proliferar escritos apologéticos o polémicos dirigidos al mundo griego, entre las que se cuentan obras como los escritos del anónimo Samaritano, la Sibila judía (c. 140 a.C.), las obras de Artápano y, eventualmente, incluso escritos de la llamada literatura intertestamental como el Libro de los Vigilantes y 1 Enoch. ${ }^{7}$

Vertida hacia el exterior, la Septuaginta permitió al judaísmo-helénico dialogar con la intelectualidad griega del período y convencer a los pensadores de su medio sobre la importancia de la Ley Mosaica y la antigüedad de su linaje; ${ }^{8}$ responder también a cuestionamientos levantados por intelectuales del medio helénico como Hecateo de Abdera (S. IV a.C.), filósofo griego discípulo de Pirrón y contemporáneo de Alejandro Magno. Fueron también estas Escrituras las que sustentaron los trabajos de proselitismo emprendidos por el judaísmo helénico, largamente abordados por la teología contemporánea. ${ }^{9}$ Ya en el siglo I d.C., el judeo-heleno Filón de Alejandría presentará a la Septuaginta como un regalo del judaísmo al mundo griego (Mos. 2.31), una ley que atrae y gana la atención de todos, bárbaros y griegos, habitantes de las tierras y las islas, naciones del este y el oeste, de Europa y Asia, de todo el mundo habitado de fin a fin (Mos. 2.20).

En las próximas páginas realizaremos una indagatoria preliminar en torno a la genealogía de dos voces griegas -eídolon y daímon - que serán utilizadas como moneda de cambio para la extensa polémica contra los llamados dioses ajenos al interior del llamado Antiguo Testamento. Situando algunas coordenadas sobre los usos griegos del concepto, nos proponemos reflexionar en torno a la transformación de ambos conceptos al interior de la Septuaginta y, por sobre todo, observar los potenciales polémicos asociados a dicha transformación y legados al cristianismo.

Se propone, como hipótesis primaria, que las voces griegas eidolon ( $(\imath \delta \omega \lambda \circ \nu)$ y daimon ( $\delta \alpha i \mu \omega \nu$ ) no ingresan a la Septuaginta por criterios de pertinencia traductológica, como alternativas más o menos precisas a ciertas voces hebreas, sino como recursos heurísticos llamados a contestar a la pregunta por los dioses ajenos. Ambos conceptos $-\varepsilon i \delta \omega \lambda$ $\delta$ y $\delta \alpha i \mu \omega \nu$ - serán utilizados para traducir no una sino numerosas voces hebreas, y lo harán -restrictivamente- solo en aquellos pasajes donde se trata sobre los dioses ajenos o su culto. Se sostiene,

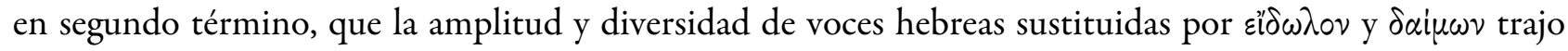
consigo la acumulación de diversas retóricas polémicas sobre los dioses ajenos, que otorgarán los fundamentos hermenéuticos y el sustento canónico para la construcción de las futuras voces ídolo y demonio. 


\section{EÍDOLON}

Las letras del Antiguo Testamento, desde el libro del Génesis hasta la tardía Sophia Salomonos (S. III a.C.), contienen una polémica religiosa de larga data, empujadas por aquello que J. Assmann ha dado a llamar "distinción mosaica", la aplicación de criterios de verdad y falsedad al terreno de las realidades religiosas.

${ }^{10}$ El primero, relato cosmogónico, se presenta como una narrativa contrastante con los mitos antiguos, especialmente del medioambiente semítico. El segundo, la Sabiduría de Salomón, surge en un ambiente helénico y se dirige contra él, estableciendo la que es, con toda posibilidad, la primera teoría sistemática sobre la religión de las naciones, desde el culto a la naturaleza ( $\mathrm{Sab}$. 13:1-9) hasta la divinización de reyes, temática inevitable en tiempos helénicos. En contraste con las prácticas de traducibilidad religiosa similares a la interpretatio graeca, este concepto de verdad enfático se reconocerá incompatible con las experiencias de lo sagrado vividas por las demás culturas, y relegará estas formas religiosas ajenas al ámbito de lo falso, en virtud de aquella distinción establecida -y sellada- en el pacto y la alianza del Monte Sinaí.

Los dioses de la gentilidad ocupan un lugar central en la ley mosaica. La expresión hebrea ä\#êrîm élōhîm ("otros dioses"), contenida en el Segundo Mandamiento dado por YHWH a Moisés, ${ }^{11}$ es una de las expresiones utilizadas para referir a los dioses ajenos al pueblo de Israel, y se encuentra aparejada de voces similares como 'Elohe nê\#ār ("dios extranjero"), ${ }^{12}$ élōhîm \#ä\#ā̌šrm ("Nuevos dioses"). ${ }^{13}$ En la, expresiones

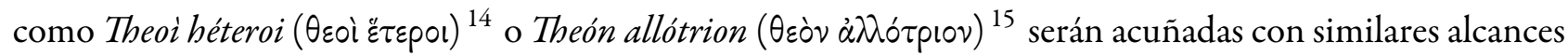
de sentido. Naturalmente, no son las únicas. Diversas voces hebreas y semitas convergen en las Escrituras del Antiguo Testamento para remitir directa o indirectamente a los dioses de las naciones, declarados falsos o sujetos a la soberanía de YHWY. La traducción emprendida por los redactores de la Septuaginta en Alejandría, capital del mundo helénico, será una oportunidad para sincronizar sus escritos con el nuevo medioambiente.

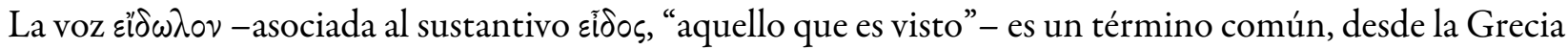
arcaica hasta el helenismo en que se inscribe el judaísmo alejandrino, para designar un tipo de imagen o de

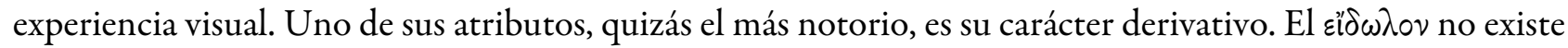
por sí mismo sino como semblanza de una fuente primaria, como imagen imprecisa de un original. Es por tanto, tenido como oscuro (amaurós) y asimilado a la sombra (skiá). ${ }^{16}$

En el contexto griego arcaico, aquellas imágenes, sueños y reflejos solo pueden ser producidos por los dioses, fabricantes de imágenes (eidolópoios), consignando lo divino a escala de la mirada humana. ${ }^{17}$ En $O d .11 .476$, cuando Odiseo es reprendido en el inframundo por el espíritu de Aquiles, este se refiere a los habitantes del Hades como muertos insensibles ( $v \varepsilon$ kpoi $\alpha \phi p a \delta \varepsilon \dot{\varepsilon} \varepsilon$ ) y semblanzas de los mortales ( $\beta p \circ \tau \tilde{\omega} \nu \varepsilon i \hbar \delta \omega \lambda \alpha \kappa \alpha \mu \dot{o} v \tau \omega \nu)$. En otro pasaje $(I l .23,100)$, el espíritu (psykhê) de Patroclo pide a Aquiles -en sueños- ser enterrado pronto. El hijo de Peleo intenta abrazarlo en vano, mientras Patroclo se desvanece bajo tierra como humo. Aquiles

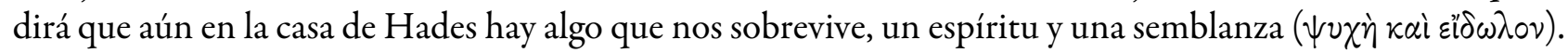

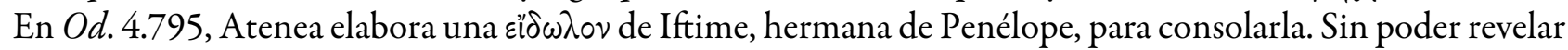
el destino de Odiseo, la imagen de Iftime se desvanecerá en las corrientes de viento ( $\dot{\varsigma} \varsigma \tau \nu \circ \dot{\alpha} \varsigma \dot{\alpha} \nu \varepsilon \dot{\varepsilon} \mu \omega \nu)$. Años

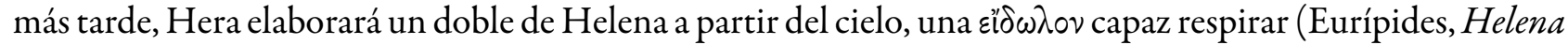
33). Como apunta J. P. Vernant, cuando los dioses son asimilados a los humanos, los conceptos utilizados

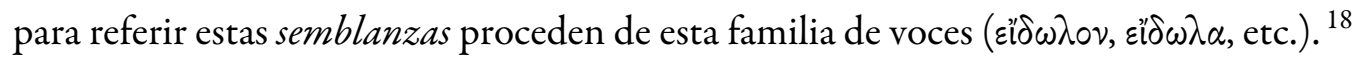

Es sabido que en el esquema general de la obra de Platón, este concepto caerá en desprestigio. Conservará, como en tiempos homéricos su carácter de noción derivativa, secundaria, pero se volverá un concepto insostenible por la preeminencia que adquirirá la verdad de la i $\delta \dot{\varepsilon} \alpha$ por sobre la atracción de la pura apariencia.

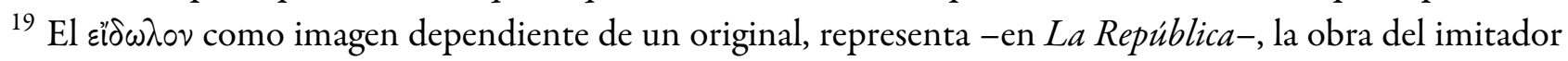
o mimetiké, que no puede fabricar sino copias de un original. ${ }^{20}$ Incluso cuando la pregunta por el estatuto ontológico de la imagen lleve al $\varepsilon^{\prime} \delta \omega \lambda$ ov de Platón a perder densidad, la semblanza nunca dejará de ser 
considerada una entidad diferente de aquello que realmente es, una imagen que no se confunde con su original y por lo tanto es. ${ }^{21}$ En la Alegoría de la Caverna (Rep. 7.532b), recordemos, las sombras que observan los

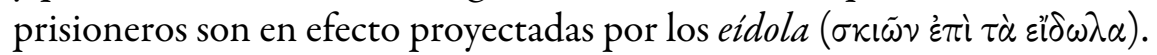

Como ha señalado Griffith, $\varepsilon^{\prime \prime} \delta \omega \lambda$ ov podía ser usado para referir a imágenes sagradas. ${ }^{22}$ Sus ejemplos escasos, pero significativos- son posteriores tanto a la Septuaginta como a la obra de Platón. En la obra de Diodoro Sículo (S. I a.C.), el rey Filipo II había dispuesto ei̋ $\delta \omega \lambda \alpha$ de los doce Olímpicos en las celebraciones por el matrimonio de su hija Cleopatra, en las procesiones hacia los juegos celebratorios, disponiendo entre ellos un treceavo ziઈ $\omega \lambda$ ov donde figuraba, representado en talle divino, el propio Filipo (Bib. Hist. XVI.92.5). En su Antigüedades Romanas, el historiador griego Dionisio Halicarnaso (60-7 a.C.) habla del pequeño templo de Velia, en el corazón de Roma, donde reposaban dos figuras de dioses troyanos -posiblemente los Dioscuri- y señala haber visto muchas otras imágenes de dioses ( $\left.\varepsilon^{\prime} \delta \omega \lambda \alpha \tau \tilde{\omega} \nu \theta \varepsilon \tilde{\omega} \nu\right)$ en templos antiguos, en todas ellas siendo representadas ambas divinidades troyanas (Antiq. Rom. I.68.2). Festivales a Adonis, celebradas exclusivamente por mujeres, exigían la disposición de representaciones de la divinidad y, en las letras de Plutarco (46 -120 d.C.) estas representaciones llevan el nombre de عi $\delta \omega \lambda \alpha$ y están destinadas a su entierro, como parte de los ritos mortuorios asociados a las A $\delta \dot{\omega} v i \alpha$ (Nic. 13.11). Contrario a lo que podría parecer, los usos de $\varepsilon i \delta \omega \lambda$ ov en estos pasajes no buscan hacerle equivalente a un agálmaton ("imagen consagrada de la divinidad”) sino simplemente indicarlo como semblanza de otra realidad. Esta distinción queda magistralmente expuesta por Polibio en su Historia. No es posible, dice el rey Antioco a Daphne: "enumerar la cantidad de $\dot{\alpha} \gamma \alpha \lambda \mu \dot{\alpha} \tau \omega \nu$ por $\varepsilon \hat{\imath}^{\delta} \omega \lambda \alpha$ de todos los seres que han sido dichos o tenidos por dioses" (Hist. 30.12.13-15).

El $\varepsilon i \delta \omega \lambda \circ v$, como realidad física, tendrá un lugar central en la Septuaginta, en virtud de una antigua polémica sobre las formas materiales de los dioses ajenos. En el Salmo 115, los dioses son considerados simples figuras manufacturadas ( $\breve{a} \# a b$, luego $\varepsilon^{\prime \prime} \delta \omega \lambda \alpha$ ), incapaces de hablar pese a tener boca, de ver pese a tener ojos, de usar sus pies para moverse o su nariz para oler. Mientras YHWH habita el cielo y crea el mundo, los ídolos de las naciones ( $\tau \dot{\alpha} \varepsilon \hat{\imath} \delta \omega \lambda \alpha \tau \tilde{\omega} \nu \dot{\varepsilon} \theta \nu \tilde{\omega} \nu$ ) son plata y oro, obras del trabajo del hombre (1-7). Transportados en los hombros de los gentiles, son depositados en lugares desde donde no pueden volver a moverse, sin poder responder a lo que se les pregunta, ${ }^{23}$ tanto por su mutismo como por su incapacidad para inteligir. ${ }^{24} \mathrm{La}$ tardía Sabiduría de Salomón retomará y extenderá esta discusión, describiendo detalladamente los procesos de confección de los $\varepsilon^{\prime} \delta \omega \lambda \alpha a$ través de las obras del carpintero (13:11-19), del alfarero y el orfebre (15:7-13), del artista que exageró la belleza de lo representado (14:18-21).

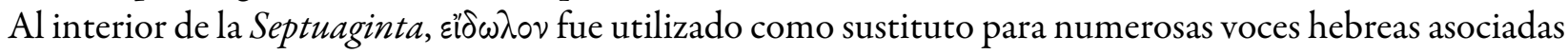
a esta polémica. Se cuentan entre ellas pesel ("forma labrada"), 'eseb- 'oseb ("dar forma”) y la tríada massêtāh - ne\#sek - nāsî\# asociadas a la producción de objetos metálicos por fundición y relacionadas a la raíz nasak, "verter". Pertenecen también a este conjunto las voces ta\#nît (“copia” o "patrón”), dèmût ("semejanza") y těmûnâ, con similares alcances. ${ }^{25}$

El ídolo como objeto material del culto será, sin embargo, solo una de las dimensiones que este concepto heredará de la Septuaginta. Un segundo conjunto de nuevas voces hebreas serán reemplazadas por la voz $\varepsilon i \delta \omega \lambda$ ov, teniendo como único denominador común el constituirse en expresiones infamantes u ofensivas. Se cuentan entre ellas las voces hebel ("insustancial, inútil”), šeqer (“engaño, falsedad”), saw (“vacío, vanidad"), mip\#le\#e\# ("forma abominable"), siqqûs ("cosa detestable”) y seqes, utilizado específicamente para remitir a los animales impuros que podrían contaminar a quienes los comiesen. También neologismos como gillûlim -elaborado a partir de la raíz gel-galal (“excremento") - y que será utilizada para establecer asociaciones entre los dioses y el estiércol animal, o la ingeniosa construcción elîlîm, creada a partir del adjetivo elîl ("débil", "inútil") y la partícula de plural para establecer similitudes fonéticas con la voz élōhîm (“dioses").

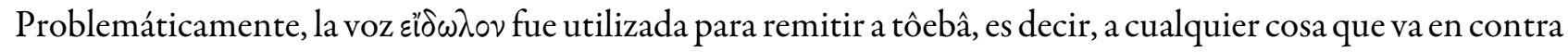


de las convenciones religiosas y que viola el pacto de Israel con el Dios Verdadero, expandiendo notoriamente su área de dominio. ${ }^{26}$

La presencia de la voz $\varepsilon i \delta \omega \lambda$ ov al interior de la LXX no responde, evidentemente, a criterios pertinencia traductológica. No solo el arco de voces hebreas traducidas excede largamente las posibilidades de término, sino que es posible observar cómo las mismas expresiones hebreas serán traducidas por otras voces griegas cuando el contexto de polémica religiosa no esté presente. En Jueces 17 se relata la historia de Micaia, un hombre que habitaba en el monte de Efraín junto a su madre, a quien había robado mil cien monedas de plata. Tras devolver el dinero voluntariamente, la madre decidió dedicar el dinero a YHWH, realizando una imagen de fundición (massê\#\#̄̄h), una imagen labrada (pesel), en tiempos en que no había rey en Israel "y cada cual hacía lo que le parecía" (1-6). Tras la llegada de un sacerdote de levita, los "ídolos" serán preservados en casa de Micaia y solo saldrán de ella cuando sean robados por los hombres de Dan y portado finalmente por el levita hasta una nueva ciudad (Jueces 18: 14-20). En este paisaje, de piedad heterodoxa, los redactores de la Septuaginta no utilizarán $\varepsilon i \delta \omega \lambda$ ov para reemplazar a massê\#äh o pesel, sino, con toda precisión, las voces

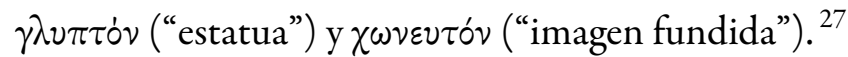

Los usos de $\varepsilon i \delta \omega \lambda$ ov al interior de la Septuaginta dependen pues de la necesidad teológica que alimenta su redacción. En un pasaje clave como la prohibición de hacer imágenes -segundo mandamiento- la voz

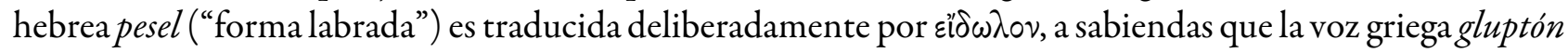
( $\gamma \lambda v \pi \tau \dot{0} \nu)$ posee exactamente el mismo significado que pesel y que fue, de hecho, utilizada en 43 de las 54 apariciones de pesel durante la traducción de la obra. ${ }^{28}$ Gluptes $(\gamma \lambda u ́$ ú $\tau$ s) significa "escultor, tallador, escultor o grabador", el verbo glupho ( $\gamma \lambda \dot{\nu} \phi \omega)$ señala la acción de esculpir y glúphanos ( $\gamma \lambda \dot{\nu} \phi \alpha \nu \circ \varsigma)$ refiere al instrumental utilizado para tallar o grabar un objeto.

Tampoco harán uso extensivo de la voz ágalma $(\ddot{\alpha} \gamma \alpha \lambda \mu \alpha)$, un concepto clave en el lenguaje cultual helénico y que remite, precisamente, al objeto que en virtud de su notoria calidad y confección inspira deleite en el espectador y es apto para representar a los dioses. ${ }^{29} \mathrm{La}$ voz, que deriva del verbo agállo $(\dot{\alpha} \gamma \dot{\alpha} \lambda \hat{\lambda} \omega)$ y se encuentra asociada a la idea de "honrar" o "exultar", es utilizada para referir a formas producidas por manos humanas para glorificar a los dioses y provocarles agrado en los templos. Un $\ddot{\alpha} \gamma \alpha \lambda \mu \alpha$ era capaz de irradiar un resplandor que pertenecía a la esfera de lo inmortal -lo divino-, sin renunciar a su significación material, uniendo la noción de que un objeto podía estar vivo y emanar los efectos taumatúrgicos ( $\theta \alpha \tilde{\nu} \mu \alpha$, "maravilla") producidos por una manufactura superior. ${ }^{30}$

Los redactores de la Septuaginta evitarán escrupulosamente el uso de la voz \#ǐcóv, será escrupulosamente evitada como alternativa de traducción para representaciones e imágenes de los dioses ajenos. Mientras

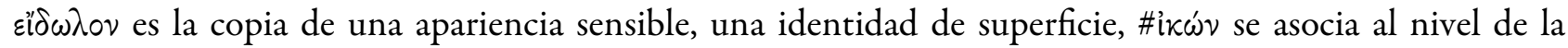
estructura profunda y del significado,31 reservando su uso para episodios fundamentales como Gen. 1.26, donde la criatura singular de la creación, el hombre, será denominado imagen (zíxóva) de YHWH (Gen. $1.26) .{ }^{32}$

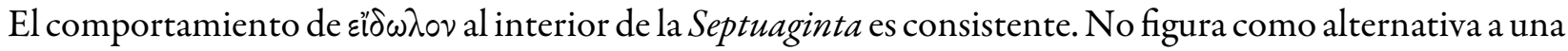
voz hebrea particular, ni se encuentra asociada a un único campo semántico, sino que emerge como reemplazo de numerosas voces cuando el contexto lo exige. Es un instrumento de polémica religiosa, que no describe

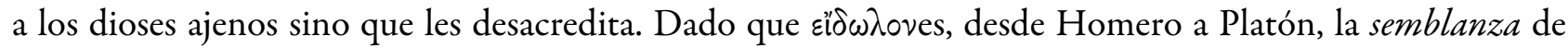
una fuente primaria, la operación traductológica hizo de los dioses -o sus agálmata-, formas derivativas de una fuente original que serán, en la misión Paulina y con toda posibilidad en el proselitismo judeo-helénico, el Génesis, acto creador de Dios. Las consecuencias de este giro hermenéutico son profundas y podrán ser observadas en contextos de misión histórica tan tardíos como los del siglo XVI americano.

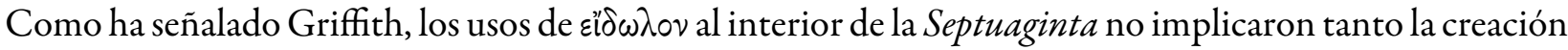
de una expresión nueva, como la excepcional utilización de esta voz para aludir a los dioses mismos, algo

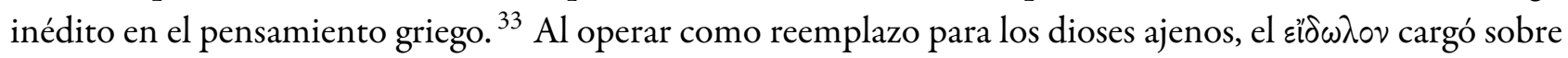


sí el peso de siglos de polémica religiosa, las hermenéuticas ensayadas sobre los dioses que no ven ni caminan, sobre los dioses débiles y vacíos, sobre los dioses-excremento. Los distintos pasajes de las Escrituras donde voces hebreas fueron sustituidas por $\varepsilon i \delta \omega \lambda$ $\mathrm{v}$ otorgaron una densidad que este concepto, significativamente,

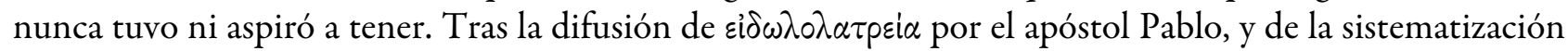
emprendida por Tertuliano en su De Idolatria (190-220 d.C.), el concepto ocupará un lugar central en la misión histórica. Toda evangelización, desde la misión a los suevos de Gallaecia por Martín de Braga (S.VI) hasta los trabajos de Bernardino de Sahagún entre los nabua de México, un milenio más tarde, tendrán como eje y motor una polémica religiosa enraizada en las letras del Antiguo Testamento.

\section{DAÍMON}

El problema de los dioses ajenos ('élōhîm'ä\#êrîm, 'Elohe nê\#är) tiene lugar al interior de las Escrituras hebreas, a través de formas más directas que las voces infamantes asociadas al eidolon. Sus libros contienen los nombres de numerosas divinidades del ambiente semítico, extraídas de los mitos de su medioambiente para enfatizar la soberanía de Yahveh, a partir de la transferencia de sus atributos sagrados [Ba'al, Rephesh], de ostentación de su autoridad [Liwyä\#ān, Rahab] o de su caracterización e instrumentalización como agentes negativos [Šêtîm, Rephesh, Lîlî\#, Se'irim].

La composición de la Septuaginta traerá consigo la revisión de estos distintos sustratos, y permitirá a los redactores sincronizar los escritos con su nuevo medioambiente. Los nombres de algunas divinidades semitas arcaicas como las divinidades Bá al, el dios canaanita Mōle\# (Mlk, "rey"), y la divinidad filistea de la fertilidad Dagon serán transcritos al griego (Mo $\lambda \chi^{\prime},{ }^{34} \Delta \alpha \gamma \dot{\omega} \nu,{ }^{35} \mathrm{~B} \alpha \dot{\alpha} \lambda{ }^{36}$ ), conservando sus funciones y su sentido original. Otras desaparecerán por completo. ${ }^{37}$ La mayor parte de ellas, sin embargo, serán objeto de reflexiones por parte de los redactores judeo-helenos, dando lugar a la adaptación de voces griegas en sustitución de los nombres propios de raíz semítica.

En Isaías 34:14 la divinidad femenina Lîlı̈\# -adaptación de la Lilitú mesopotamia- será traducida por

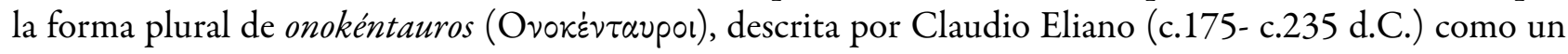
antropoide, pese a que la voz misma se encuentra asociada a los asnos y los centauros. ${ }^{38}$ Las serpientes acuáticas semitas ligadas al ciclo de la creación, como Liwyä\#ān, Tannîn y Rahab serán sustituidas por expresiones como drákōn $(\delta \rho \dot{\alpha} \kappa \omega \nu, \delta \rho \dot{\alpha} \kappa o v \tau \alpha)$ en diversos pasajes ${ }^{39}$ y la voz déndra $(\delta \dot{\varepsilon} v \delta \rho \alpha)$ será utilizada en la $L X X$ (Isa.17.8 y 27.9) para referir a los 'ǎšêrîm, objetos de culto-posiblemente un árbol o un poste de madera- asociado a la diosa canaanita de la fertilidad ' $A \#$ she\# ra \#h, esposa de El en la literatura ugarítica (bajo el nombre de \#A\#irat) y posible consorte de YHWH durante parte de la historia de Israel. ${ }^{40}$

La voz griega $\delta \alpha i \mu \omega \nu$ y sus derivados ingresan a la Septuaginta como parte de esta polémica general sobre los dioses, aunque de forma indirecta. Serán, en primer término, la moneda de canje para dos voces, los sể̇îm y los śấrîm. En un cántico compuesto por YHWH y escrito por Moisés (Deut.31.15-22), el profeta exalta la grandeza del Dios único y el amparo que dio a Jacob, cuando este yacía en la soledad del desierto (Deut.32.10).

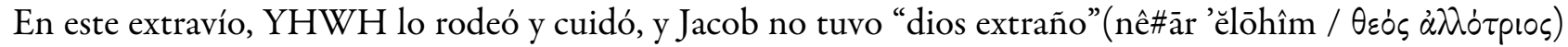
ante sí (Deut. 32.12). El Dios Único, lo hizo subir sobre las alturas de la tierra y prosperar, y en tal prosperidad el pueblo, Jeshurun -voz poética de Israel- "tiró coces" y llena de los manjares prodigados por Él, comenzó a

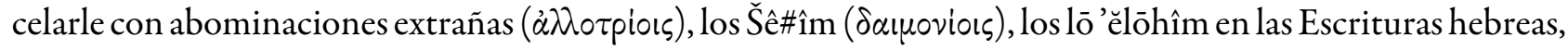
Oz̉ $\theta \varepsilon \dot{e}$ en la Septuaginta (Deut. 32.17). El motivo de la rebeldía es tomado posteriormente en Salm. 106, cuando se denuncia a los renuentes de Israel. Aquellos que en algún momento tuvieron envidia de Moisés y de Aaron en Egipto, los que luego cambiaron la gloria de YHWH por la representación de un buey que

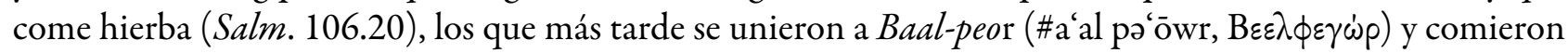
los sacrificios de los muertos, son los mismos que se mezclaron con las naciones y aprendieron sus obras,

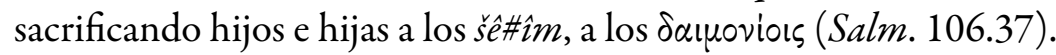


Sobre la voz $\check{S}$ ê\#ı̂m, se trata de una adaptación de la entidad $\check{S} e ̂ d u$, un espíritu protector sumerio representado -junto a su contraparte femenina Lamassu- bajo la forma de colosales toros alados, y emplazados en las entradas de los templos y construcciones, como guardianes destinados a evitar el ingreso de espíritus dañinos a los hogares. ${ }^{41}$ Desencajado de su contexto original, el antiguo Šêdu pasará a transformarse, bajo la expresión $\breve{S}$ êtim, en un concepto polémico, clave para elaboraciones demonológicas tanto en Qumran como en el posterior judaísmo rabínico. ${ }^{42}$

El origen del segundo colectivo, los Śềrîm, es más difícil de establecer. El consenso de los especialistas es traducir esta voz como "seres peludos" -eventualmente como "cabras"-, y se les considera una referencia genérica a dioses animales del entorno. ${ }^{43} \mathrm{~N}$. H. Snaith ha presentado evidencia para asociar a los Ś êrî̀m con divinidades canaanitas de fertilidad, los llamados "Baales" de lluvia o de tormenta. ${ }^{44}$ Eynikel, por su parte, señala que la proximidad de los Ś ềrîm con Lîlî\# (en Deut. 34.14) y las asociaciones semánticas asociadas a los pasajes en que es descrito, sugieren que es necesario ampliar la definición de Śễrîm a la dimensión mitológica que tuvo en su contexto de origen. ${ }^{45}$

En la llamada Profecía de Babilonia, es revelada a Isaías la destrucción de esta ciudad por los Medos, presentados acá como instrumentos de YHWH (Isa. 13.17). El relato es vívido y extenso (Isa. 13:22). La tierra asolada y despoblada, nunca será habitada por el hombre, sino por seres de lo salvaje, como la bənōw\#

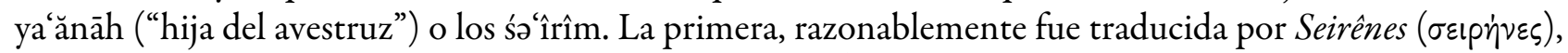
las mujeres-aves de la literatura homérica. Los segundos, Se îrî̀m, será sustituidos por daluóvia (Isa. 13.21).

Una segunda repetición del motivo lo encontramos en Isaias 34. YHWH, dice el redactor, está airado contra todas las naciones (gōwyim, $\varepsilon^{\prime} \theta \nu \eta$ ) y las destruirá, las entregará al matadero (1-2). Sus arroyos se convertirán en brea, y su polvo en azufre, y su tierra en brea ardiente que no se apagará ni de día (9-10). También se adueñarán de ella animales del espacio salvaje, como la bənōw\# ya ănāh -traducida esta vez

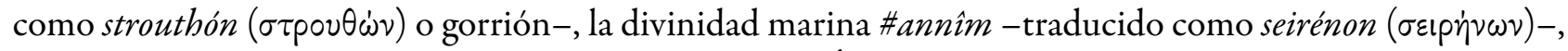

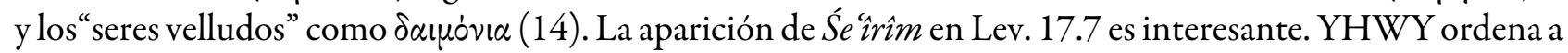
Moisés hablar a Aarón y a todos los hijos de Israel, prohibiendo los sacrificios a los Śềrîm. En lugar de utilizar $\delta \alpha i \mu \omega \nu$, los utilizarán el adjetivo mátaios, voz surgida del adverbio mátèn ("sin propósito", "desprovisto de fuerza, éxito o resultado”). ${ }^{46}$ La Vulgata registrará daemonibus de todas formas.

Hasta este punto la voz $\delta \alpha i \mu \omega v s e$ ha utilizado como moneda de canje para denominaciones colectivas como Šêtîm y Śếrîm, un rasgo que sin duda estará presente en la posterior voz demonio. Sin embargo, fuera del espacio de estos, el uso de la voz daimon es utilizada en pasajes notoriamente disímiles. En Isaías 65.11, inicialmente se señalaba que los que abandonan a YHWH sirven la mesa a Ga\#, la Fortuna. ${ }^{47}$ Tras la Septuaginta, será un daimónion el receptor de las ofrendas, una idea que será recogida y sintetizada por Pablo en su famoso pasaje: "no podéis beber la copa del Señor, y la copa de los demonios; no podéis participar de la mesa del Señor, y de la mesa de los demonios" (1 Cor. 10.21) y que sin duda tuvo un notorio impacto posterior. En un canto (Salm. 91.6), se dirá que el Altísimo ('elyōwn) librará a su pueblo de la peste destructora, y se reemplazará una figura concreta a este "plaga" o "pestilencia" con un agente o actuante concreto, $\delta \alpha$ l 0 viov. En

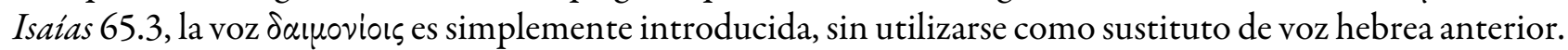

Quizás ningún pasaje expandirá los potenciales de esta voz que el Salmos 96, uno de los llamados Salmos de entronización, ${ }^{48}$ destinados a exaltar la regencia, soberanía y el honor del Dios Único Verdadero ante las naciones. ${ }^{49}$ Canta al Señor, dice el Salmista, y bendice su nombre. Anuncia el buen mensaje $\left(\varepsilon \dot{\alpha} \alpha \gamma \varepsilon \lambda \lambda_{i \zeta \varepsilon \sigma \theta \varepsilon)^{50}}\right.$ de su salvación, día a día. Anuncia $(\dot{\alpha} \nu \alpha \gamma \gamma \varepsilon i \lambda \alpha \tau \varepsilon)$ entre las naciones $\left(\ddot{\varepsilon}^{\theta} \theta \nu \varepsilon \sigma \iota\right)^{51}$ su gloria. Él es temido por sobre todos los dioses, porque todos los dioses de las naciones son 'élîlîm (dioses inútiles). ${ }^{52}$ Los traductores de la Septuaginta no escogerán voces como pseudes o el mismo mataios de Lev. 17.7, sino dos alternativas. Mientras

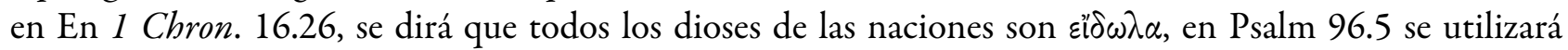




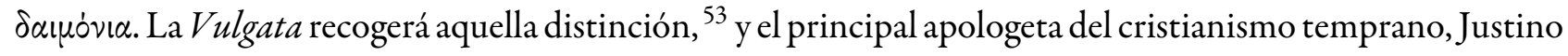
el Mártir, utilizará este pasaje para sus elaboraciones teóricas. ${ }^{54}$

En la Grecia arcaica, la voz $\delta \alpha i \mu \omega \nu$ puede designar a un dios $(\theta \varepsilon \dot{c} \varsigma)$ pero, frecuentemente, de forma relativa e imprecisa. En Il. 1.201-240 Atenea se presenta ante Aquiles como enviada por la diosa Hera para persuadirlo de levantar la espada contra a Agamenón; tras lograr su propósito, se dice que Atenea volvió al Olimpo, al

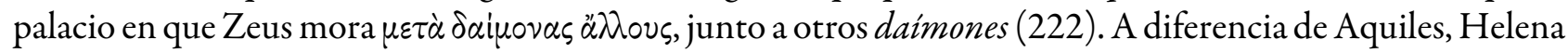
discute duramente con Afrodita, y provoca la exaltación de la hija de Zeus. Helena, temerosa, vistió una túnica blanca y siguió en silencio a la diosa, que guió el camino ( $\tilde{p} \rho \chi \varepsilon \delta \varepsilon \dot{\varepsilon} \delta \alpha i \mu \omega \nu)$. Su uso más difundido es, $\sin$ embargo, para referir a un poder divino que se manifiesta a sí mismo. Al combatir con Apolo, Diomedes es denominado daimoni isos por igualar a los dioses (Il. 5.438, 459) y el mismo título recibe Patroclo cuando

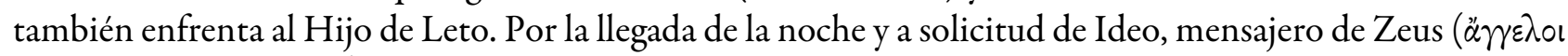
$\Delta$ เòs), Héctor pedirá a Áyax Telamonio luchar al día siguiente, hasta que la divinidad los separe ( $\delta ı$ ¿

En los usos post-homéricos, el concepto es objeto de desarrollos, siendo el de Hesíodo (c. 700 a.C.) el más

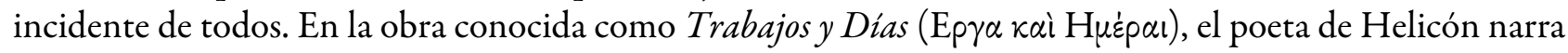
la creación del ser humano y las etapas que transcurrieron hasta la quinta generación, aquella en que él nació. En los inicios del poema (109-126), Hesíodo relata la historia de los primeros humanos, un pueblo dorado que vivía en tiempos de Cronos, cuando este aún gobernaba en el cielo. Como dioses vivieron sus días sin envejecer, ajenos a todo daño o mal, viviendo en campos de granos abundantes, y compartiendo sus frutos. En los planes del gran Zeus estaba el que los primeros humanos fuesen transformados en $\delta \alpha i \mu o v \varepsilon \varsigma$, guardianes ( $\phi \hat{\nu} \lambda \alpha \kappa \varepsilon \varsigma)$ del ser humano $(\dot{\alpha} \nu \theta \rho \dot{\omega} \pi \omega \nu)$. Cubiertos por la invisibilidad, caminan por la tierra para velar sobre los juicios de las gentes, y para entregar riquezas y prosperidad. Este honor, señala Hesíodo, recibieron de $\Delta$ iós

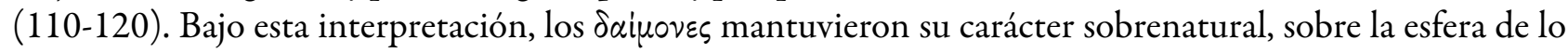
humano, pero claramente bajo los theoi.

Libros de la llamada "literatura intertestamental"son sin duda receptores de estos desarrollos. El Libro de los Vigilantes (S. III a.C.), contenido en 1 Enoc, es sin duda una de las exégesis más tempranas del confuso pasaje de Gen. 6.1-4, y establece una relación directa entre los "Hijos de Dios" y entidades similares a los ángeles llamados egrē\#goroi (“vigilantes”, "despiertos”). Diversos autores han evidenciado que los relatos de 1 Enoch 6-10 se encuentran sincronizados con el contexto helénico en el que fueron redactados, ${ }^{55}$ especialmente a la luz de algunos procesos históricos que impactaron significativamente en las comunidades judías. ${ }^{56}$ Tanto Asael como Prometeo se rebelan contra una divinidad celeste, e introducen conocimientos -especialmente la metalurgia- a la humanidad. Ambos son, significativamente, castigados con ataduras y piedras. La asociación fue en tal medida explícita que años más tarde Clemente de Alejandría citará textualmente el relato de Prometeo. ${ }^{57}$ Lo mismo puede decirse de los paralelos existentes entre la Titanomaquia griega y el rol de los gigantes en la historia de Semihazah, una temática que circula en las elaboraciones del contexto judeo-helénico como queda en evidencia en la traducción griega de Judith 16.7, donde el hebreo Rephaim ("Gigante") es traducido como Titanon, pese a estar disponible la voz Gigantes (Гi $\gamma \alpha \nu \tau \varepsilon \varsigma) .{ }^{58}$ El capítulo 19, posiblemente uno de los registros más tardíos, ${ }^{59}$ presenta a los Vigilantes como espíritus $[\pi \nu \varepsilon v ́ \mu \alpha \tau \alpha]$ capaces de adoptar diversas formas en la tierra, y que instigarán a la humanidad al culto

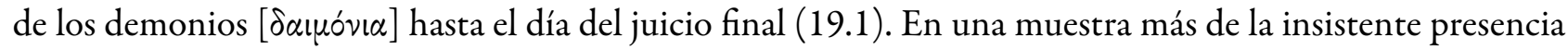
del universo mítico helénico, los redactores señalan que las esposas de los ángeles -de las que no tenemos

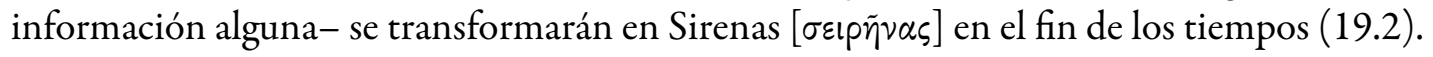

El Libro de los Jubileos, escrito en el siglo I a.C., contiene algunos desarrollos complementarios a la tradición enoica. En esta obra intertestamental, los demonios son representados como entidades negativas y denominados de distintas maneras: "demonios" (7.27, 10.12), "demonios sucios" (10.1), "espíritus" (10.5, 10.8, 11.5), “espíritus perversos” (10.3), “espíritus malignos” (10.13, 12.20), “espíritus maliciosos” (11.4), 
"los malignos" (10.11), entre otras fórmulas. ${ }^{60}$ Sirven, principalmente a dos propósitos: constituyen, en primer lugar, agentes de justicia divina, sometiendo a prueba a la humanidad, poniendo a Dios en conocimiento de los pecados del hombre, y destruyendo - con permisión divina- a los perversos. Más importante para nuestro análisis, los demonios gobiernan a las naciones gentiles son objeto de adoración por parte de las mismos pueblos y son las potencias que permiten la magia en las naciones paganas. ${ }^{61}$ Su vínculo con las naciones queda notablemente retratado en el capítulo 15. De acuerdo al relato, Dios habría creado espíritus para gobernar sobre las naciones y mantenerlas apartadas de él, pero sobre el Pueblo de Israel no puso ángel ni espíritu alguno, pues solo él gobierna a su pueblo elegido (Jub. 15.31-32). ${ }^{62}$ Ecos de esta hermenéutica pueden encontrarse, abundantemente, en la literatura de la primera evangelización de América. ${ }^{63}$

\section{Conclusiones}

Las ideas discutidas en este estudio, iniciales como fueron, nos han permitido aquilatar la importancia que supuso el traspaso de las Escrituras hebreas a la koiné griega en los fundamentos de la misión histórica. Resulta

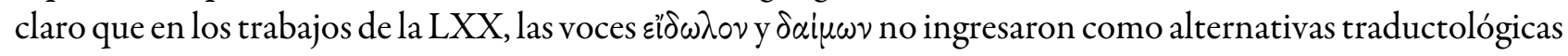
para conceptos definidos; el amplio y disímil conjunto de voces hebreas sustituidas por ambas es el ejemplo más evidente. Ingresaron en virtud de un contexto que demandó su presencia y restringió sus usos, la querella con los dioses ajenos.

Siendo moneda de cambio para diversos estratos de polémica al interior del Antiguo Testamento, las voces $\varepsilon \delta^{\prime} \delta \omega \lambda \circ \nu$ y $\delta \alpha i \mu \omega \nu$ cargaron sobre sí los pesos de distintas agendas polémicas, adquiriendo un grosor inusitado para conceptos originales liminales y opacos. Eł’ $\delta \omega \lambda$ ov legó a Ídolo su relación con las formas materiales del culto, y una idea general de impotencia o debilidad asociada a los dioses extranjeros; $\delta \alpha i \mu \omega \nu$ entregó a Demonio su naturaleza categorial, colectiva, así como una imagen asociada a aspectos exclusivamente negativos. En ambos casos, las voces permitieron definir ontológicamente a los dioses ajenos ( $\mathrm{Salm}$. 96.5, 1 Cron. 16.26).

Ponderar el impacto de las hermenéuticas contenidas en las voces ídolo y demonio resulta de vital importancia para comprender procesos de gran envergadura como es la expansión del cristianismo por el orbe. Aun a siglos de distancia, para los misioneros de la primera evangelización de América no es San Agustín ni Santo Tomás el modelo teórico seguido para hacer frente a la abundante idolatría americana, sino el Antiguo Testamento. Domingo de Vico (1519-1555), misionero entre los mayas de Mesoamérica, parafrasea pasajes de Salm.115. 2-8, Isaías 46.7, Baruc 6.7, para enfrentarse a los dioses locales; Bernardino de Sahagún (1499-1590) inserta capítulos completos de la Sabiduría de Salomón en su Historia General y los traduce al náhuatl para usarlos directamente en los trabajos de la misión. A fines del XVI, José de Acosta (1540-1600) instruirá a los evangelizadores de los Andes Centrales a acudir directamente a las Escrituras para tomar desde allí los recursos necesarios para su extirpación.

\section{ReFERENCIAS}

Aeliani. (1858). De Natura Animalium. Varia Historia, Epistolae e Fragmenta. Paris: Editore Ambrosio Firmin Didot. Assmann, J. (2003). La distinción mosaica o el precio del monoteísmo. Madrid: Akal.

Bamberger, B. J. (1968). Proselytism in the Talmudic Period. New York: Ktav Publishing House.

Bauckham, R. (1985). The fall of the Angels as the Source of Philosophy in Hermias and Clement of Alexandria. Vigiliae Christianae, 39, 313-330.

Braude, W. G. (1940). Jewish proselytizing in the First Five Centuries of the Common Era: the Age of Tannaim and Amoraim. Providence: Brown University Press. 
Brandt Bradshaw, W. (1964). Demonology in Hebrew and Jewish tradition. A study in New Testament origins. Thesis submitted for the Degree of Doctor of Philosophy at the University of St. Andrews.

Bartelmus, R. (1979). Heroentum in Israel und seiner Umwelt. Zurich: Theologischer Verlag.

Bedell, C. H. (1998). Mission in Intertestamental Judaism. En W. J. Larkin y J. F. Williams (Eds.), Mission in the New Testament: an evangelical approach (pp. 21-29). Markynoll, N.Y: Orbis Books.

Belfiore, E. (1984). A Theory of Imitation in Plato's Republic. Transactions of the American Philological Association, 114, 121-146.

Borgen, P. (1998). Proselytes, Conquest, and Mission. En P. Borgen (Ed.), Recruitment, Conquest, and Conflict: Strategies in Judaism, Early Christianity and the Greco-Roman World (pp. 57-77). Atlanta: Scholars Pr.

Botha, P. J. (1998). The Enthronement Psals: a claim to the world-wide honour of Yahweh. Old Testament Essays 11/1, 24-39.

Carlenton Page, J. (1996). Jewish proselytism ant the Time of Christian Origins: Chimera or reality? JSNT, 62, 65-103.

Collins, J. (1997). Seers, Sibyls, and Sages in Hellenistic-Roman Judaism. Leiden: Brill.

Collins, J. (1998). The apocalyptic imagination: an introduction to Jewish apocalyptic literature. Grand RapidsCambridge: William B. Eerdmans Publishing Company.

Collins, J. (2000). Between Athens and Jerusalem: Jewish Identity in the Hellenistic Diaspora. Grand Rapids-Cambridge: William B. Eerdmans Publishing Company.

Curtis, E. (1992). Idol, Idolatry. En D. N. Freedman (Ed.), The Anchor Bible Dictionary (Vol. 3, pp. 376-381). New York: Yale University Press.

Dever, W. (1984). Asherah, Consort of Yahweh? New Evidence from Kuntillet \#Ajrûd. Bulletin of the American Schools of Oriental Research, 255, 21-37.

Dickson, J. P. (2003). Mission-commitment in ancient judaism and in the pauline communities: the Shape, Extent and Background of Early Christian Mission. Tu\#bingen: Mohr Siebeck.

Dines, J. (2004). The Septuagint. London-New York: T\&T Clark.

Eynikel, E. (1996). The reform ofkingJosiah and the composition of the Deuteronomistic History. Leiden-New York: Brill. Feldman, L. (1993 [1932]). Jew and the Gentile in the Ancient World. Princeton: Princeton University Press.

Feldman, L. H. (1994). Jewish proselytism. En H. W. Attridge \& G. Hata (Eds.) Eusebius, Christianity and Judaism (pp. 372-408). Detroit: Wayne State University Press.

Fernandez Marcos, N. (2000). The Septuagint in Context: Introduction to the Greek Version of the Bible. Leiden: Brill. Freedman, D. (Ed.). (1992). The anchor bible dictionary. New York-London: Doubleday.

Frey-Anthes, H. (2008). Concepts of Demons in Ancient Israel. Die Welt des Orients, Bd. 38, 38-52.

Gelb, I.; Landsberger, B. \& Oppenheim, L. (1960). The Assyrian Dictionary of the Oriental Institute of the University of Chicago. Chicago: University of Chicago.

Gernet, L. (1981). The Anthropology of Ancient Greece. London: Johns Hopkins University Press.

Glasson, F. (1961). Greek influence in Jewish eschatology, with special reference to the Apocalypses and Pseudepigraphs. London: SPCK.

Griffith, T. (2002). EI $\Delta \Omega \Lambda \mathrm{ON}$ as Idol in non-Jewish and Non-Christian Greek. The Journal of Theological Studies, 53(1), 95-101.

Griffiths, T. (2002). Keep yourselves from Idols: A New Look at 1 John. Sheffield: Sheffield Academic Press.

Hengel, M. (1974). Judaism and Hellenism: Studies in their Encounter in Palestine during the Early Hellenistic Period. Philadelphia: Fortress.

Jeremias, J. (1958). Jesus' Promise to the Nations. London: SCM Press.

Keel, O. \& Uehlinger, C. (1998). Gods, Goddesses, and Images of God in Ancient Israel. Minneapolis: Fortress. 
Marcos de Pinotti, G. (2004). Filosofía versus sofística en el Sofista de Platón. En María Isabel Santa Cruz (Ed.), Diálogo con los griegos: Platón, Aristótles y Plotino (pp. 77-91). Buenos Aires: Colihue.

Martin, D. (2010). When Did Angels Become Demons? Journal of Biblical Literature, 129(4), 657-677.

Morgenstern, J. (2002). The Doctrine of Sin in the Babylonian Religion. San Diego: Book Tree.

Muraoka, T. (2009). A Greek-English lexicon of the Septuagint. Louvain-Paris-Walpole: Peeters.

Nickelsburg, G. (1977). Apocalyptic and Myth in 1 Enoch 6-11.JLB, 96, 383-405.

Reed, A. Y. (2004). The trickery of the Fallen Angels and the demonic mimesis of the divine: aetiology, demonology, and polemics in the writings of Justin Martyr. Journal of Early Christian Studies, 12(2), 141-171.

Reed, A. Y. (2005). Fallen Angels and the History ofJudaism and Christianity. The Reception of Enochic Literature. New York: Cambridge University Press.

Reed, A. Y. (2009). Enochic and mosaic traditions in Jubilees: The evidence of angelology and demonology. En G. Boccaccini y G. Ibba (Eds.), Enoch and the mosaic Torah: the evidence of Jubilees (pp. 353-368). Grand Rapids (Mich.): William B. Eerdmans Publishing Company.

Saïd, S. (1987). Deux noms de l'image en grec ancien: idole et icône. Comptes-rendus des séances de l'Académie des Inscriptions et Belles-Lettres, 131(2), 309-330.

Schultz, J. (1981).Judaism and the Gentile Faiths: Comparative Studies in Religion. Rutherford: Fairleigh Dickinson University Press.

Snaith, N. H. (1975). The Meaning of \#\#\#\#\#. Vetus Testamentum, 25(1), 115-118.

Steiner, D. (2011). Images in Mind: Statues in Archaic and Classical Greek Literature and Thought. Princeton: Princeton University Press.

Suter, D. (1979). Fallen Angel, Fallen Priest: The problem of family purity in 1 Enoch 6-16. HUCA, 50, 115-135.

Valenzuela, E. (2017). Infiernos deshabitados: fronteras ontológicas y estrategias de traducción en léxicos y vocabularios coloniales (Andes Ss. XVI-XVII, Chile Ss. XVII-XVIII). En V. Favarò, M. Merluzzi, G. Sabatini (Eds.), Fronteras: procesos y prácticas de integración y conflicto (siglo XVI-XIX) (pp. 181-194). Madrid-México: Fondo de Cultura Económica.

Vanderkam, J. (2001). Guides to Apocrypha and Pseudepigrapha. The book of Jubilees. Sheffield: Sheffield Academic Press.

Van der Toorn, K.; Becking, B. \& Van der Horst, P. (1999). Dictionary of the Deities and Demons in the Bible (DDD). Leiden: Brill.

Vernant, J. P. (1990). Figuration et image. Mètis, Anthropologie des mondes grecs anciens, 5, 225-238.

Wuest, K. (1947). Studies from the Greek New Testament for the English Reader. U.S.: William B. Eerdmans Publishing Company.

\section{Notas}

1 Este artículo forma parte de los avances del proyecto Postdoctoral Fondecyt No3170037, Las armas del convencimiento: diálogos misionales entre la edad media (s.vi-viii) y la primera evangelización de América (S.XVI), desarrollado en la Universidad de Chile bajo el patrocinio de la prof. María Eugenia Góngora. El presente estudio no contó con financiamiento adicional.

2 Fernandez Marcos, 2000, pp. 19-20. Schultz, 1981, p. 155.

3 Collins, 2000, p. 5.

4 En sus componentes, la obra contiene los libros de la Torah hebrea -Génesis, Éxodo, Levítico, Números y Deuteronomio-, los libros proféticos, sapienciales y las escrituras que completan la Tanakh, así como también nuevas composiciones esta vez directamente en griego- que solo sobrevivirán en el canon cristiano. Pertenecen a este conjunto las adiciones a Esther, Jeremias y Daniel; 1-3 Macabeos, Tobit, Judith, I Esdras, Sabiduria de Salomón, Sirach y los llamados Salmos de Solomon.

5 Dines, 2004, pp. 142-143.

6 Dines, 2004, p. 28. 
7 Sobre este punto, ver: Glasson, 1961; Hengel, 1974 y Suter, 1979, pp. 115-135.

8 Dines, 2004, pp. 44.

9 Sobre este tema, ver: Dickson, 2003; Bamberger, 1968; Braude, 1940; Feldman, 1932; Feldman, 1994; Carlenton Paget, 1996, pp. 65-103; Borgen, 1998, pp. 57-77; Bedell, 1998, pp. 21-29 y Jeremias, 1958.

10 Assmann, 2003, p. 9.

11 Ex. 20:3.

12 Deut. 31:16, Josh 22:20, Gen. 35:2.

13 Deut. 32:17, Judges 5:8.

14 Ex. 20:3.

15 Salm. 44:20-21.

16 Saïd, 1987, pp. 313.

17 Saï, 1987, pp. 437.

18 Vernant, 1990, p. 231.

19 Saïd, 1987, p. 317.

20 Belfiore, 1984, pp.129-130.

21 Marcos de Pinotti, 2004, p. 87.

22 Griffith, 2002, pp. 95-101.

23 Isa. 46:7, Baruc 6:7.

24 Isa. 44:9, Baruc 6:40-41.

25 Curtis, 1992, p. 378.

26 Curtis, 1992, p. 378.

27 Muraoka, 2009, p. 739.

28 Griffiths, 2002, pp. 32-33.

29 Steiner, 2011, pp. 16.

30 Gernet, 1981, pp. 73 y ss.

31 Vernant, 1990, pp. 231; Saï, 1987, pp. 311 y 313.

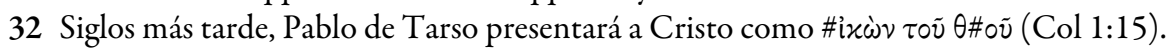

33 Griffith, 2002, p. 101.

342 Reyes 23:10,13 (god). Jerem 32:35, Amos 5:26.

35 Jueces 16:23, 1 Samuel 5:2, 1 Cron. 10:10, Isa. 46:1.

36 Num. 23:41, Jueces 2:13 - 6:25, 1 Reyes 16:31, 2 Reyes 1:21.

37 Se pueden mencionar entre ellas al dios guerrero Rešep\#, de culto ampliamente difundido en Egipto y en Ugarit, y ăzāzêl -la cabra del desierto-, desaparecerá en Lev. 16 sin dejar huella alguna. Brandt Bradshaw, 1964, pp. 81-82.

38 "De onocentaura quidem mihi nunc est animus explicare, quae auditione et fama accepi: Eam ipsam scilicet homini similem esse; et pilis prolixis faciem ejus ambiri; collum et pectus humanam speciem similitudinemque gerere...”, Aeliani, 1858, Lib.17.9.

39 Job 7:12, Jeremias 51:34, Exequiel 32:2, Isa 34:13, Salm. 104:26.

40 Dever, 1984, pp. 21-37. Una visión general del problema véase en Keel \& Uehlinger, 1998, pp. 229-48.

41 Morgenstern, 2002 [1905], p. 25. Gelb, Landsberger \& Oppenheim, 1960, p. 99.

42 Frey-Anthes, p. 42; Martin, 2010, p. 658.

43 Freedman, 1992, p. 139.

44 Snaith, 1975, p. 118.

45 Eynikel, 1996, pp. 236-238.

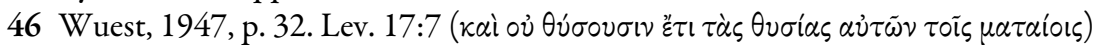

47 Es fortuna (Gad) una divinidad bastante antigua y con un culto extendido. Una de las primeras apariciones de Ga\# puede observarse en inscripciones proto-canaanitas de la Era del Bronce, y su culto en transjordania se ha fechado como pre-israelí, siendo Tell ed-Duweir uno de los centros de culto de esta deidad. Posteriores menciones a esta divinidad pueden encontrarse diseminadas en Nora-Sardinia (siglo IV-III A.C.) y en Ibiza-España (c.180 A.C.), y las inscripciones de Palmira revelan intentos de traducción entre esta divinidad y la Tyche (Fortuna) griega. Van der Toorn; Becking; Van der Horst, 1999, p. 340.

48 Salmos 47, 93, 96, 97 y 99.

49 Botha, 1998, p. 25.

50 El griego de la Septuaginta reemplaza al hebreo, Basseru (\#\#\#\#\#\#\#\#\#\#) «llevar noticias».

51 El griego de la Septuaginta reemplaza al hebreo, goyim «no-israelí ».

52 De elîl, "débil", "inútil" y la partícula de plural -îm.

53 "Omnes enim dii populorum idola Dominus autem caelos fecit" (1 Chron 16:26) "quoniam omnes dii gentium daemonia at vero Dominus caelos fecit” (Salm. 95:5). 
54 Reed, 2004, p. 141.

55 Sobre este punto, ver: Nickelsburg, 1977, pp. 383-405; Bartelemus, 1979, pp. 161-166; Bauckham, 1985, pp. 313-330; Collins, 1998, pp. 50-51; Reed, 2005, p. 39.

56 Para un análisis sobre el impacto de las tecnologías militares helénicas en el imaginario judaico durante el inicio de las conquistas alejandrinas, ver: Hengel, 1974, pp. 12-18; Collins, 1997, pp. 60-65.

57 Bauckham, 1985, p. 324.

58 Glasson, 1961, p. 63.

59 Reed, 2005, p. 58.

60 Brandt Bradshaw, 1964, pp. 159.

61 Reed, 2009, p. 357.

62 "For there are many nations and many peoples and all belong to him. He made spirits rule over all in order to lead them astray from following him. But over Israel he made no angel or spirit rule because he alone is their ruler" Vanderkam, 2001, p. 93.

63 Valenzuela, 2017, pp. 181-194.

\section{BY-NC-SA}

